exploring health facilities in Oman to see what sort of doctors were needed. He also consulted the Ministry of Health and visited the schools.

Teaching is in English, but many students do not speak good English and intensive language teaching needs to be undertaken in the first two years of the course. The students have been taught to learn by rote at school and have few manual skills and no "problem solving skills" (in the jargon of medical education). They find it difficult to gather information and to think in concepts and may come from a culture that does not encourage disagreement. They also find it hard to accept that there are no reliable answers to many questions.

Small group sessions, some of them built round showings of Jonathan Miller's television series The Body in Question, have helped to encourage the necessary "depth of understanding." In the first two years students undertake various electives and a compulsory programme on first aid. One project that was particularly effective was a survey of trachoma by students in the town of Fanja. They were taught how to examine the eye and how to conduct a scientific survey; they then typed the data into computers themselves. The project gave them confidence as well as providing useful data.

Another difficulty arises in teaching men and women

British Medical Journal London WC1H 9JR Richard Smith, MB, assistant editor move around on the ground floor of the university and the women on the first floor. But already the barriers are breaking down, and it is the women who are excelling.

The anxiety about reaching international standards surfaces in plans for research. The new professor of surgery, Professor A Daar, has spent years doing research in the department of surgery in Oxford, and he has plans to encourage research of a high standard that will also be relevant to the needs of Oman. $\mathrm{He}$ expects that researchers will eventually spend about $60 \%$ of their time on directed research programmes relevant to Oman. The rest of their time will be devoted to their own research.

The possibilities for research are endless, especially in local epidemiology. Dr M A Jaffer, a consultant surgeon, has begun a cancer register, and $\mathrm{Dr} C$ Thomas, a plastic surgeon, has collected data on burns and on cleft lips and palates, but they are still at the stage of posing questions. Is gastric cancer so common in men because of the Omani habit of drinking up to 60 cups of coffee a day? And are cleft lips and palates so common because of consanguinity?

I thank the government of Oman for inviting me to its country and the many people who gave me their time. Particularly attentive hosts were Douglas Roy and Shaun Brogan, who not only drove me around but also corrected my manuscript. I also thank Alex Paton, who used his knowledge of the Middle East to make beneficial cuts in the article.
Medical Research Council Epidemiology and Medical Care Unit, Northwick Park Hospital, Harrow, Middlesex HA1 3UJ Joy Townsend, MSC, scientific staff Sandra Dyer, MSC, scientific staff

W R S North, PHD, scientific staff

T W Meade, FRCP, director

\section{Northwick Park Hospital}

Mary Piper, FRCP, consultan physician in geriatric medicine A O Frank, MRCP, consultant physician in rheumatology and rehabilitation

Correspondence to: Joy Townsend.

\title{
Reduction in hospital readmission stay of elderly patients by a community based hospital discharge scheme: a randomised controlled trial
}

\author{
Joy Townsend, Mary Piper, A O Frank, Sandra Dyer, W R S North, T W Meade
}

\section{Abstract}

Study objective-To compare a community support scheme using care attendants with standard aftercare for their effects on independence and morale of elderly patients discharged from hospital and on their use of health and social services.

Design-Randomised controlled study of cohort of patients over 75 discharged to their own homes.

Setting-District general hospital and community.

Patients - Total of 903 patients (mean age 82, 25\% over 85).

Interventions-Total of 464 patients received support from care attendants on first day at home and for up to $\mathbf{1 2}$ hours a week for two weeks. Support comprised practical care, help with rehabilitation, and organising social help. The remaining 439 patients received standard aftercare.

End point-Difference between two groups of 7\% in hospital readmission rates or one point on activities of daily living scale (power $80 \%$, significance level $5 \%$ ).

Measurements and main results-Three months after the initial discharge 763 patients were interviewed $(84 \%)$. There were no significant differences between the two groups in physical independence (activities of daily living scale), in measures of morale (Philadelphia scale), or in death rates. Hospital readmission rates within 18 months of discharge, however, were significantly higher in the control group and they spent more days in hospital (mean; control group $\mathbf{3 0 . 6}$ days, support group $17 \cdot 1$ days $; p=0 \cdot 014)$. Of the patients living alone who were followed up for 18 months $21(15 \%)$ receiving standard aftercare were readmitted more than twice compared with $6(5 \%)$ supported by care attendants $(\mathbf{p}<\mathbf{0 . 0 1})$.

Conclusions-If the findings are confirmed, and the policy extended to all patients over the age of 75 living alone, an average health district might expect either to save about 23 hospital beds at a net annual saving of about $£ 220000$ in the short term or to increase available beds by this number.

\section{Introduction}

Growing concern about the management of frail elderly patients after they have left hospital ${ }^{1.3}$ has led to the development of several schemes for their support. ${ }^{+5}$ Harrow Health Authority and Harrow social services department agreed that joint funding resources should be used to finance three care attendants appointed by the social services department to help patients aged over 75 years being discharged from any ward of Northwick Park Hospital to the central area of Harrow. The scheme was to be evaluated to establish whether it improved the independence and morale of elderly patients or affected their use of health and social services. ${ }^{6}$

\section{Patients and methods}

The care attendants were to see patients before they were discharged, on their first day at home, and for up to 12 hours a week for two weeks. Their role was, firstly, to provide practical care; secondly, to help with rehabilitation by encouraging patients to look after themselves and get around, both inside and outside 
their homes, and, thirdly, to organise help from family, friends, and statutory services. The aim was to return them to maximal independence as soon as possible by leaving them adequately supported and with appropriate aids for daily living. The care attendant service was independently evaluated from April 1984 to April 1986 using a randomised controlled factorial trial, analysed by intention to treat. The first 903 patients over 75 years old admitted from a defined area of central Harrow and discharged from any ward of Northwick Park Hospital to their own homes were recruited to the study, representing $23 \%$ of all those over 75 in the study area. ${ }^{8}$

On admission, patients were randomly allocated to receive either support from care attendants or standard aftercare. If a patient previously randomised to receive the care attendant service was readmitted he or she was offered the same service at each subsequent discharge. Similarly, those randomised to receive standard aftercare received standard support provided by social services after each admission. The two groups were randomly divided into two subgroups for assessment by a factorial design (figure). One subgroup was

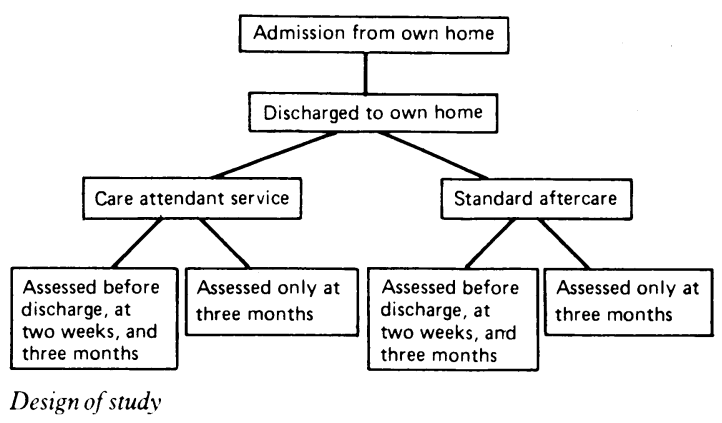

assessed before discharge, and two weeks and three months after discharge, whereas the other group was assessed only after three months. This design permitted the evaluation of any effect of the assessment itself, as discovery of a particular need during the assessment might have increased the likelihood of that need being met. As far as possible the assessors were kept unaware of which patients had received support from care attendants. The care attendant service was offered irrespective of a patient's circumstances, because it was thought that patients who might benefit most would be those for whom it was erroneously assumed that independent support was available. The trial also aimed to identify characteristics of patients most likely to benefit from such a service.

Physical independence was measured at each assessment with an activities of daily living scale; this is precise and has little variability either between assessors or between assessment in hospital or at home. ${ }^{9}$ Psychological morale was measured with the Philadelphia geriatric morale scale developed by Storandt et $a l^{10}$ and adapted by Challis for use with British patients.

TABLE I-Demographic characteristics

\begin{tabular}{lccc}
\hline & $\begin{array}{c}\text { Group receiving care } \\
\text { attendant support } \\
(\mathrm{n}=464)\end{array}$ & $\begin{array}{c}\text { Group receiving } \\
\text { standard aftercare } \\
(\mathrm{n}=439)\end{array}$ & $\begin{array}{c}\text { Total } \\
\text { patients } \\
(\mathrm{n}=903)\end{array}$ \\
\hline Mean age (years) & $82 \cdot 0$ & $81 \cdot 8$ & $81 \cdot 9$ \\
No $\%$ over 85 years & $120(26)$ & $102(23)$ & $222(25)$ \\
Sex: & $173(37)$ & $151(34)$ & $324(36)$ \\
Male & $291(63)$ & $288(66)$ & $579(64)$ \\
Female & $179(39)$ & $171(39)$ & $350(39)$ \\
No $\%$ fully mobile & $185(40)$ & $202(46)$ & $386(43)$ \\
No $(\%)$ living alone & $11 \cdot 6^{\star}$ & $11 \cdot 9 \dagger$ & $11 \cdot 7$ \\
Mean mental test score before discharge & $20 \cdot 8^{\star}$ & $20 \cdot 5 \dagger$ & $20 \cdot 7$ \\
Mean activity of daily living score before discharge & $10 \cdot 2^{\star}$ & $10 \cdot 6 \dagger$ & $10 \cdot 4$ \\
Mean geriatric morale score before discharge & & & \\
\hline
\end{tabular}

$\star_{\mathrm{n}}=187 ; \mathrm{tn}=153$
Cognitive function was measured with a mental test score."

Information about social conditions, demographic data, community support networks during the day and night, use of health and social services, and experience of accidents was also collected. Deaths, readmissions to hospital, diagnoses, and drugs being taken on discharge were noted. Data about the use of home care services and "meals on wheels" were obtained from the social services, and all other health and social service contacts were monitored independently. Details of time spent with patients and services provided were documented by the care attendants.

It was decided to include enough patients in the trial to be able to detect differences between the two groups of $7 \%$ in hospital readmission rates or one point on the activities of daily living scale with a power of $80 \%$ and significance level $5 \%$. A previous survey in the district suggested that it would take about two years to recruit the 900 patients required. ${ }^{12}$ End points were to be estimated for the subgroups of those living alone and those over 85 years old.

\section{Results}

Patients - The first 903 patients to be discharged to their own homes were entered into the trial. They were from all wards and were not concentrated in the geriatric or long stay wards; 464 were randomised to receive support from care attendants and 439 to receive standard aftercare. Three months after their initial discharge 763 patients $(84 \%)$ were interviewed. Sixty two $(7 \%)$ had died, $32(4 \%)$ refused to be interviewed, $10(1 \%)$ were in residential care, seven $(0.8 \%)$ were too ill, four $(0.4 \%)$ were in hospital, and three missed their appointments. The remaining $22(2 \%)$ were not interviewed for other reasons. The percentages interviewed from the two groups were similar ( $84 \%$ and $85 \%$, respectively).

Table I gives the demographic data of the two groups. There was little difference between the groups in these respects, or in the predischarge activity of daily living scale, mental test score, or morale score. There were no significant differences in the end points between those randomised to one or three interviews and so no apparent effect of assessment. The data were therefore pooled for analysis.

There was a small decrease $(0.4$ points $)$ in physical independence among those receiving support from care attendants during the first two weeks after discharge that was sustained at three months, and a slight increase in independence among those receiving standard aftercare $(0.2$ points $)$ that increased at three months $(0.4$ points $)$, but none of these differences was significant. There was a slight increase in morale among the care attendant group $(0 \cdot 1$ points at two weeks and three months) and a fall among those receiving standard aftercare $(0.2$ points), but the difference $(0.3$ points) was not significant. Both groups registered an average 0.3 point improvement in cognitive function in the three months after discharge from hospital.

Deaths-Fifty nine (7\%) of the patients had died by three months, $34(7 \%)$ among those receiving support from care attendants and $25(6 \%)$ among those receiving standard aftercare; $172(19 \%)$ had died by a year after discharge, $91(20 \%)$ and $81(19 \%)$, respectively. These differences were not significant.

Readmission rates - Within three months of discharge $105(23 \%)$ among the care attendant group and 102 (23\%) from the control group were readmitted. The difference was not significant $(95 \%$ confidence intervals for the difference $-4 \cdot 9 \%$ to $+6 \cdot 1 \%)$. Those readmitted during this period spent an average of 17 days in hospital. 
Eighteen months after discharge, however, there was a significant difference between the number of readmissions among those supported by care attendants and those who had received standard aftercare $\left(\chi^{2} 15 \cdot 6\right.$, df $\left.7, p=0.03\right)$ (table II). Forty three patients who had received standard aftercare (13.9\%) were readmitted more than twice during the 18 months compared with only $23(6 \cdot 7 \%)$ of those supported by care attendants $\left(\chi^{2} 9.3\right.$, df $1, \mathrm{p}<0.01 ; 95 \%$ confidence interval for the difference $2 \cdot 5 \%$ to $11 \cdot 8 \%$ ). Those who had received standard aftercare spent an average of $25 \%$ more days in hospital than those supported by care attendants (mean 22.8 days compared with 18.2 ) after the initial discharge.

Patients who lived alone - The differences in the total length of stay in hospital between the groups were even greater for the particularly vulnerable subgroup of those living alone ( $43 \%$ of all patients). Table III shows that patients who had received standard aftercare, including those not readmitted, spent $79 \%$ more days in hospital within 18 months of their initial discharge than did those who received support from care attendants (30.6 days compared with $17 \cdot 1$ days, $\mathrm{p}=0.014$, Fisher's method of randomisation to establish the significance of a $t$ test $\left.^{13}\right)$. Twenty one $(15 \%)$ of those who had received standard aftercare were readmitted more than twice compared with six $(5 \%)$ of those supported by care attendants $\left(\chi^{2} 8 \cdot 8\right.$, df $1, \mathrm{p}<0.01 ; 95 \%$ confidence interval for the dif-

TABLE II-Cumulative number of readmissions to hospital within 18 months of discharge

\begin{tabular}{|c|c|c|c|}
\hline $\begin{array}{c}\text { No } \\
\text { of } \\
\text { readmissions }\end{array}$ & $\begin{array}{l}\text { Group receiving care } \\
\text { attendant support } \\
\qquad \begin{array}{c}(\mathrm{n}=341) \\
\text { No }(\%)\end{array}\end{array}$ & $\begin{array}{c}\text { Group receiving } \\
\text { standard aftercare } \\
(\mathrm{n}=310) \\
\text { No }(\%)\end{array}$ & $\begin{array}{l}\text { Odds ratio- } \\
\text { standard } \\
\text { aftercare/care } \\
\text { attendant }\end{array}$ \\
\hline None & $165(48)$ & $137(44)$ & 0.9 \\
\hline$\geqslant 1$ & $176(52)$ & $173(56)$ & $1 \cdot 1$ \\
\hline$\geqslant 2$ & $72(21)$ & $77(25)$ & $1 \cdot 2$ \\
\hline$\geqslant 3$ & $23(7)$ & $43(14)$ & $2 \cdot 1$ \\
\hline$\geqslant 4$ & $12(4)$ & $20(7)$ & 1.9 \\
\hline$\geqslant 5$ & $7(2)$ & $8(3)$ & $1 \cdot 2$ \\
\hline$\geqslant 6$ & $1(0 \cdot 3)$ & $5(2)$ & $5 \cdot 3$ \\
\hline$\geqslant 7$ & 0 & $3(1)$ & \\
\hline
\end{tabular}

TABLE III-Cumulative number of readmissions within 18 months-patients living alone

\begin{tabular}{|c|c|c|c|}
\hline No of readmissions & $\begin{array}{l}\text { Group receiving care } \\
\text { attendant support } \\
(\mathrm{n}=132) \\
\text { No }(\%)\end{array}$ & $\begin{array}{l}\text { Group receiving } \\
\text { standard aftercare } \\
(\mathrm{n}=136) \\
\text { No }(\%)\end{array}$ & $\begin{array}{l}\text { Odds ratio- } \\
\text { standard } \\
\text { aftercare/care } \\
\text { attendant }\end{array}$ \\
\hline $\begin{array}{l}\text { None } \\
\geqslant 1 \\
\geqslant 2 \\
\geqslant 3 \\
\geqslant 4 \\
\geqslant 5 \\
\geqslant 6 \\
7\end{array}$ & $\begin{array}{l}60(46) \\
72(55) \\
25(19) \\
6(5) \\
1(0 \cdot 8) \\
1(0 \cdot 8) \\
0 \\
0\end{array}$ & $\begin{array}{c}54(40) \\
82(60) \\
38(28) \\
21(15) \\
13(10) \\
5(4) \\
3(2) \\
2(1)\end{array}$ & $\begin{array}{r}0.9 \\
1.1 \\
1.5 \\
3.4 \\
12.0 \\
4.6\end{array}$ \\
\hline Mean days in hospital (including those not readmitted) & $17 \cdot 1^{\star}$ & $30 \cdot 6^{\star}$ & 1.79 \\
\hline
\end{tabular}

${ }^{\star} \mathrm{p}=0.014$, Fisher's method of randomisation.

TABLE IV-Average use of health and social services during the three months after initial discharge from hospital

\begin{tabular}{lccc}
\hline & $\begin{array}{c}\text { Group receiving care } \\
\text { attendant support } \\
(\mathbf{n}=464)\end{array}$ & $\begin{array}{c}\text { Group receiving } \\
\text { standard aftercare } \\
(\mathbf{n}=439)\end{array}$ & $\begin{array}{c}\text { Odds ratio-standard } \\
\text { aftercare/care } \\
\text { attendant }\end{array}$ \\
\hline No of days in hospital & $3 \cdot 8$ & $3 \cdot 9$ & $1 \cdot 03$ \\
No of visits by district nurse & $15 \cdot 7$ & $19 \cdot 0$ & $1 \cdot 21$ \\
No of visits by home care workers & $6 \cdot 7$ & $9 \cdot 9$ & $1 \cdot 48$ \\
No of meals supplied by "Meals on Wheels" & $24 \cdot 8$ & $22 \cdot 3$ & $0 \cdot 90$ \\
No (\%) visited by general practitioner & $309(67)$ & $309(71)$ & $1 \cdot 06$ \\
No (\%) visited by social worker & $127(27)$ & $121(28)$ & $1 \cdot 01$ \\
No (\%) visited by health visitor & $45(10)$ & $45(10)$ & 1.06 \\
No (\%) visited by voluntary worker & $14(3)$ & $17(4)$ & $1 \cdot 26$ \\
\hline
\end{tabular}

^Includes the 696 patients who were not readmitted to hospital within three months. None of the differences is significant.
TABLE V-Resource implications of implementing care attendant service for patients aged over 75 in a health district with population of 250000

\begin{tabular}{lcc}
\hline & Resource & $\begin{array}{c}\text { Yearly } \\
\text { benefit }(£)\end{array}$ \\
\hline $\begin{array}{l}\text { Reduction in No of days spent in hospital } \\
\text { Care attendant service }\end{array}$ & $\begin{array}{c}6700 \text { bed days } \\
\text { Eight care attendants }\end{array}$ & $\begin{array}{r}287000 \\
-66000\end{array}$ \\
\hline Net saving & & 221000
\end{tabular}

ference $3 \cdot 9 \%$ to $17 \cdot 9 \%$ ). For those not living alone there were no significant differences in readmission rates between the groups.

Patients aged over $85-$ Eleven (19\%) of those who had received standard aftercare, who were over 85 at the time of initial discharge, and who were followed up for 18 months were readmitted more than twice compared with only six (8\%) of those supported by care attendants $\left(\chi^{2} 3.3\right.$, df $1,0.05<\mathrm{p}<0.1,90 \%$ confidence interval for the difference $0.9 \%$ to $21 \cdot 1 \%$ ). There was no significant difference between the lengths of stay in hospital. Patients over 85 were considerably more likely to live alone than those under $85(\mathrm{n}=94(53 \%)$, compared with $\mathrm{n}=229(40 \%))$.

Use of non-hospital health and social services-Other health and social services were used more by the group who had received standard aftercare during the three months following discharge (table IV). They received $48 \%$ more visits from home care workers, $21 \%$ more visits from district nurses $(66 \%$ more for those living alone), and a higher proportion had visits from the general practitioner, the social worker, the health visitor, and the voluntary worker. They had $10 \%$ fewer meals from "meals on wheels." Two thirds of the patients $(71 \%$ who had received standard aftercare and $67 \%$ of those supported by care attendants) saw their general practitioners within three months of their initial discharge $(58 \%$ of these visits took place at home, $37 \%$ in the surgery, and $5 \%$ both), over a quarter saw social workers $(27 \cdot 5 \%$ and $27 \cdot 3 \%$, respectively), and one in 10 saw health visitors $(10.3 \%$ and $9 \cdot 7 \%$, respectively). None of these differences was significant.

Resource implications-The significantly lower hospital readmission stay for those receiving the care attendant service, particularly those living alone, had substantial resource implications. The care attendant group comprised $17 \%$ of those over the age of 75 discharged in Harrow (12\% of those over 75 discharged to the average health district with a population of 250000 ). During the 18 months studied a benefit accrued of 2498 fewer days spent in hospital by those who received support from care attendants and who lived alone.

Table V shows the costs to the average health district if the scheme were extended to all patients over 75 living alone. The average total cost per inpatient day in an acute hospital was $£ 99.63$ in $1985-6$, and in the long term savings might approach this as full adjustment was made in all services including medical staff. More immediately, the fall in demand for beds is likely to result in the release of the resources of a ward or of individual beds. It is estimated for the Harrow district that the marginal cost of a ward is $43 \%$ of the average total cost (nursing, laundry, and a proportion of some other non-medical staff costs), and the marginal cost of a single bed is $11 \%$. The adoption of a care attendant discharge service for all patients over 75 years old living alone might reduce demand for hospital beds in a district by 6715 inpatient days a year, which at an average occupancy of $81 \%$ would represent 23 hospital beds valued at $£ 287000$ a year. This compares with the direct costs of the care attendants of about $£ 66000$ a year and suggests a possible net benefit of about 
$£ 220000$ a year, or a greater than threefold return to the cost of the service. In the longer term the full cost for each inpatient day could be realised and the benefit of the service could be as much as $£ 600000$ a year.

\section{Discussion}

The average difference in activity of daily living score between the groups at two weeks and three months was slight and not significant, neither were there any differences in morale or satisfaction with the discharge procedure between the two groups. The death rate was slightly higher among those who had received support from the care attendants but the difference was not significant and may have been due to a higher proportion of those over 85 years old in this group.

One of the main reasons for the trial was to test the unverified hypothesis that lack of support in the community resulted in a higher than necessary readmission rate for some patients. The results support this hypothesis and suggest that the care attendant service resulted in a reduction in the readmission rate, particularly in the longer run, and that this benefit was greatest for those living alone and those over 85 . The effect was cumulative for patients readmitted several times as the service was given at each subsequent readmission, and suggests that the greatest benefit is to those who would otherwise have several readmissions. The lower readmission stay of these patients was not the result of any element of differential admission policy between the groups, as the care attendant service was given for only two weeks after discharge whereas most readmissions occurred much later, and those responsible for admitting patients were not aware of the randomisation. Any bias would be expected to be in the other direction, as the care attendant service for those randomised to this group would only become available again if the patient were readmitted.

Under present arrangements the resource benefits of this kind of scheme would accrue to the health service, and the long term costs would be borne by the social services (although, as in this trial, in the shorter term the costs can be provided from joint funding).

Patients over 75 years of age use $40 \%$ of all hospital beds in the United Kingdom. Over $40 \%$ of these patients live alone, and more than half will be readmitted to hospital within 18 months of their discharge. The results of this trial indicate that an investment in a good post discharge care attendant service could yield considerable benefits by keeping patients at home and thus reducing demand for unnecessary readmissions to hospital; this would be of particular value at a time when resources are strained.

We thank Olive Karran, Anne Walgrove, Judith Savidge, Eva Hastings, Kae Ross Smith, Mags Harrison, Dr John Trickett, Malcolm McGreevy, Lucy O'Brien, Terry Jones, Ray Carter, the care attendants, and many colleagues in Harrow social services. The trial owes much to the energy and enthusiasm of the late Michael Brill.

\footnotetext{
1 Davies AM. Epidemiology and the challenge of ageing. Int $f$ Epidemiol 1985;14:9-21.

2 Andrews K, Brocklehurst JC. Provision of remedial therapist in geriatric medicine. Br Med f 1984;289:661.

3 Department of Health and Social Security. Research liaison groups for the elderly. Research prionities. London: HMSO, 1981.
}

4 Skeet M. Home from hospital-providing continuous care for elderly patients. London: King's Fund, 1985

5 Age Concern Greater London Health Forum. Policies, practices and projects: hospital discharge and aftercare in London. London: Age Concern, 1986.

6 Vetter NJ, Jones DA, Victor CR. Effect of health visitors working with elderly patients in general practice: a randomised controlled trial. $\mathrm{Br}$ Med $\mathcal{J}$ 1984;288:369-72.

7 Challis D, Davies B. A new approach to community care for the elderly. British foumal of Social Work 1980;10:1-18.

8 Office of Population Censuses and Surveys. Census 1981. Greater London part 1. London: HMSO, 1982.

9 Sheikh K, Smith DS, Meade TW, Goldenberg E, Brennan PJ, Kinsella G. Repeatability and validity of a modified activities of daily living (ADL) index in studies of chronic disability. Int Rehabil Med 1979;1:51-8.

10 Storandt $M$, Wittels I, Botwinick J. Predictors of a dimension of well being in the relocated healthy aged. $\mathcal{F}$ Gerontol 1975;30:97-102.

the relocated healthy aged. I Gerontol 1975;30:97-102.
11 Denham MJ, Jeffreys PM. Routine mental assessment in elderly patients. Denham MJ, Jeffreys PM. Rou
Modern Geriatrics 1972;2:275.

12 Brooke C, Yates JE, Scott BJ. Study of elderly patients after discharge. Harrow: Northwick Park Hospital, 1982.

13 Bradley JV. Distribution free statistical tests. New Jersey: Prentice Hall, 1968:68-86.

(Accepted 10 June 1988)

\section{Update box for Oxford Handbook of Clinical Medicine, p 675}

\section{Intravenous aminophylline: dosage and therapeutic monitoring}

Aminophylline must be given in the right dose to give optimum plasma concentrations without causing toxic effects (arrhythmias, hypotension). Immunoassays have enabled the monitoring of plasma theophylline concentrations and the following advice to be given.

Guidelines for continuous intravenous infusion of aminophylline after an intravenous loading dose $e^{\star}$ of $6 \cdot 0-7 \cdot 5 \mathrm{mg} / \mathrm{kg}$ over 30 minutes. (For dose of theophylline multiply by 0.85 )

\begin{tabular}{|c|c|}
\hline & $\begin{array}{c}\text { Dose of } \\
\text { aminophylline } \\
(\mathrm{mg} / \mathrm{kg} / \mathrm{h})\end{array}$ \\
\hline \multicolumn{2}{|l|}{ Children of different ages } \\
\hline Neonates with apnoea & $0.15 t$ \\
\hline$<6$ months & $0.47^{\circ}$ \\
\hline 6-11 months & 0.82 \\
\hline $1-9$ years & 0.94 \\
\hline$>9$ years & $0 \cdot 70$ \\
\hline \multicolumn{2}{|l|}{ Adults of different types } \\
\hline Smokers & $0 \cdot 70$ \\
\hline Healthy non-smokers & 0.47 \\
\hline With heart failure & 0.23 \\
\hline With liver failure & $0 \cdot 23$ \\
\hline $\begin{array}{l}\text { Taking cimetidine, ciprofloxacin, erythromycin, } \\
\text { propranolol, contraceptive steroids }\end{array}$ & $\simeq 0.23 \ddagger$ \\
\hline
\end{tabular}

*If theophyllines have been taken in previous 24 hours avoid loading dose. If plasma theophylline concentration is known and is subtherapeutic an additional loading dose may be given. You would therapeutic an additional loading dose may be given. You would by $1.7-3.5 \mu \mathrm{g} / \mathrm{ml}$

by $1 \cdot 7-3 \cdot 5 \mu \mathrm{g} / \mathrm{ml}$.

$\ddagger$ These drugs increase half life of aminophylline. Phenytoin, carbamazepine, barbiturates, and rifampicin shorten half life. Adjust dose according to plasma concentrations.

The table shows one of the more conservative of the available regimens.

Aim for a plasma concentration of $10-20 \mu \mathrm{g} / \mathrm{ml}$ $(55-110 \mu \mathrm{mol} / \mathrm{l})$. Serious toxicity (hypotension, arrhythmias, cardiac arrest) can occur at concentrations $\geqslant 25 \mu \mathrm{g} / \mathrm{ml}$. - J M LONGMORE

Principal sources

Weinberger M, Hendeles L, Ahrens R. Clinical pharmacology of drugs used for asthma. Pediatr Clin North Am 1983;28:47-75.

Rogers M. Textbook of pediatric intensive care. Baltimore: Williams and Wilkins, 1987. 